$11-22-2019$

\title{
Illustrative indicators for community health worker performance measurement
}

Frontline Health Project

Follow this and additional works at: https://knowledgecommons.popcouncil.org/departments_sbsr-rh How does access to this work benefit you? Let us know!

\section{Recommended Citation}

Frontline Health. 2019. "Illustrative indicators for community health worker performance measurement." Washington, DC: Population Council. 


\section{ILLUSTRATIVE INDICATORS FOR COMMUNITY HEALTH WORKER PERFORMANCE MEASUREMENT}

The Frontline Health project collaborates with country $\mathrm{MOH}$, USAID missions, UNICEF offices, and ICH partner NGOs to integrate 46 community health worker ( $\mathrm{CHW}$ ) performance measurement indicators into a set of priority indicators for country monitoring and evaluation frameworks.

Initiated by Ministries of Health from the $7 \mathrm{ICH}$ partner countries, a series of expert consultations led to the following indicators. Balancing pragmatism, actionability, and comprehensiveness, indicators are categorized into 7 key domains. Experts recommend including at least 1 indicator

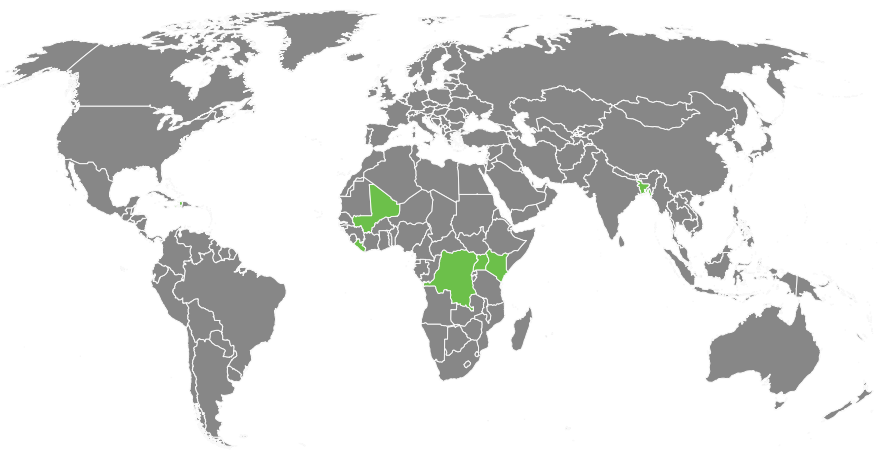
from each domain in country priority lists.

When prioritizing a shortlist from these 46 indicators, countries should consider the following:

1. Potential users and usability of the data.

a. Is data collected useful and actionable for workers on the frontlines?

b. Is data collected useful and actionable for decision-makers?

2. Data collection capacity and feasibility for routine or special studies.

a. If indicators can be routinely collected, ensure appropriate data collection systems are in place.

b. If indicators require special studies, ensure appropriate resources are in place.

3. Health information system capacity.

a. If data is collected, can action feasibly be taken to improve on the findings?

b. If not, consider re-prioritization of pragmatic, actionable information.
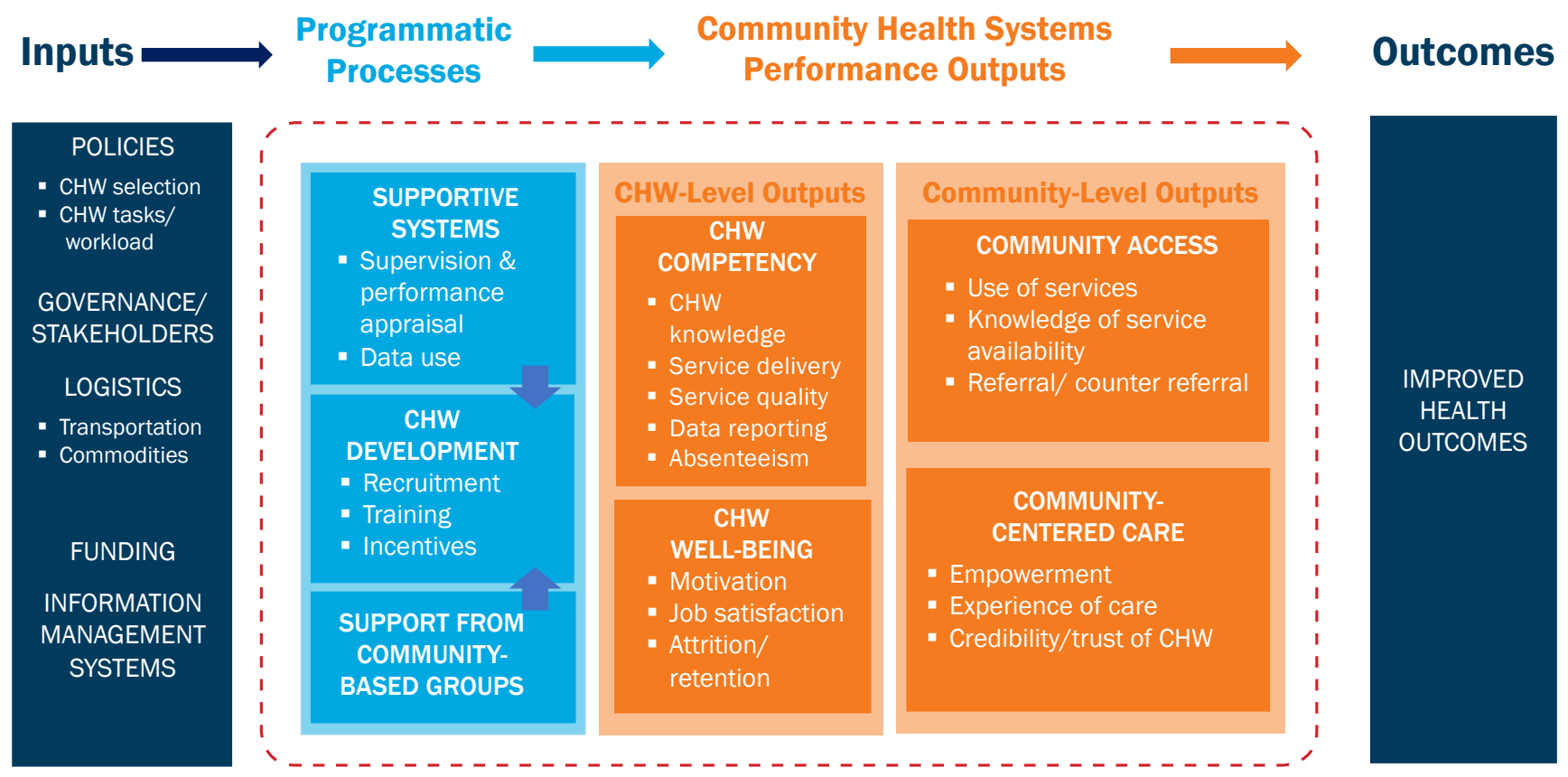

Economic Evaluation

Equity, Gender, Accountability 


\section{CHW Performance Measurement - Illustrative Indicators}

\section{Domain 1: Supportive Systems}

Sub-Domain A: Supervision and performance appraisal

1. $\quad \# / \%$ of supervisors trained in management and supervision of $\mathrm{CHWs}$

2. Ratio of $\mathrm{CHWs}$ to supervisors

3. $\# / \%$ of supervisory visits that met the quality criterion

4. Average \# of visits per supervisor to monitor/support CHW activities in the last month

5. $\# / \%$ of $\mathrm{CHWs}$ who received a supervisory visit in the last 1-3 months that includes review of reports and data collected

6. Average \# of supervisory contacts (in-person visits, phone calls, text messages, etc.) per $\mathrm{CHW}$

Sub-Domain B: Data use

7. $\quad \# / \%$ of health workers (CHWs/supervisors/health facility staff) who have access to client data AND who report using the data to make decisions about their provision of services

8. \#/\% of national/sub-national/facility/community meetings in which data (from standardized reporting platforms etc.) are discussed/reviewed

9. \#/\% of $\mathrm{CHWs}$ who have access to the client data they have collected (for follow-up) in the last 6 months

\section{Domain 2: CHW Development}

Sub-Domain A: Recruitment

10. \#/\% of $\mathrm{CHWs}$ who have been selected in alignment with selection criteria

11. \# of CHWs who have been selected/recruited

12. \#/\% of target communities/populations that have an assigned $\mathrm{CHW}$

Sub-Domain B: Training

13. \#/\% of $\mathrm{CHWs}$ who have received initial training

14. \#/\% of $\mathrm{CHWs}$ who have received follow-up training in the last two years

15. \#/\% of $\mathrm{CHWs}$ who have completed the certification program

Sub-Domain C: Incentives

16. \#/\% of $\mathrm{CHWs}$ who have received their stipend in the last month

17. \#/\% of $\mathrm{CHWs}$ who have received a specific non-financial incentive

Domain 3: Support from Community-based Groups

18. \# of planning/review meetings held at the level of the local government to discuss CHW program performance 


\section{CHW Performance Measurement - Illustrative Indicators}

\section{Domain 4: CHW Competency}

Sub-Domain A: CHW knowledge

19. $\quad \# / \%$ of $\mathrm{CHWs}$ who have passed knowledge/competency tests (following training)

20. \#/\% of $\mathrm{CHWs}$ who express that they feel confidence in their abilities to provide health education

21. \#/\% of CHWs who express confidence in their abilities to deliver basic healthcare services

Sub-Domain B: Service delivery

22. Average \# of home visits made by $\mathrm{CHWs}$ in the last month (indicator to be disaggregated by type of home visit - i.e. sick child visit, antenatal care, etc.)

Sub-Domain C: Service quality

23. $\# / \%$ of $\mathrm{CHWs}$ who correctly identified the case/health problem (as per items in a checklist)

24. \#/\% of CHWs who correctly addressed (treated) the identified health problem (as per items in a checklist)

25. \#/\% of $\mathrm{CHWs}$ with all the key stock commodities in the last reporting period

26. Average time from onset of symptom to first contact with $\mathrm{CHW}$

Sub-Domain D: Data reporting

27. $\# / \%$ of $\mathrm{CHWs}$ who submitted reports in the last month

28. \#/\% of $\mathrm{CHW}$ reports submitted that were complete/did not have missing information

Sub-Domain E: Absenteeism

29. \#/\% of $\mathrm{CHWs}$ who reported on their activities in the last month

30. \# of days $\mathrm{CHW}$ has performed at least one $\mathrm{CHW}$ responsibility in the last month

\section{Domain 5: CHW Well-Being}

Sub-Domain A: Motivation

31. Composite metric

Sub-Domain B: Job satisfaction

32. \#/\% of CHWs who expressed satisfaction with the community support they receive

33. \#/\% of $\mathrm{CHWs}$ who expressed satisfaction with the support they receive from health facility staff

Sub-Domain C: Attrition/ Retention

34. In the last 3 months, $\# / \%$ of $\mathrm{CHWs}$ who have reported on their activities 


\section{CHW Performance Measurement - Illustrative Indicators}

\section{Domain 6: Community Access}

Sub-Domain A: Use of services

35. \#/\% of households who received at least one visit by a $\mathrm{CHW}$ in the last 3 months

Sub-Domain B: Knowledge of service availability

36. \#/\% of community members that know the name of the community $\mathrm{CHWs}$

37. \#/\% of community members who can name at least 3 services that the $\mathrm{CHW}$ provides

Sub-Domain C: Referral/ counter-referral

38. $\%$ of individuals referred by $\mathrm{CHW}$ to the health facility per 100 clients seen (and subset by reasons for referral)

39. \#/\% of clients that completed the referral at the health facility (referral completion)

40. \#/\% of referred clients seen at receiving service (health facility) that is seen back at referring service (CHW) with complete counter-referral information (counter-referral)

41. Average \# of referrals made per $\mathrm{CHW}$ in the last month

\section{Domain 7: Community-Centered Care}

Sub-Domain A: Empowerment

42. Composite metric

Sub-Domain B: Experience of care

43. \#/\% of women/households who express satisfaction with services they received from the $\mathrm{CHW}$ in the last 3 months

44. \#/\% of women who report that in their interaction with the $\mathrm{CHW}$ they felt humiliated or disrespected (scale 1-5)

Sub-Domain D: Credibility/ trust of CHW

45. \#/\% of women/clients who report they trust the health information provided by the $\mathrm{CHW}$

46. \#/\% of women/clients who report they trust the treatment services provided by the $\mathrm{CHW}$

\section{For more information on the development of these indicators or} the Frontline Health project, please contact:

Pooja Sripad at psripad@popcouncil.org

or

Ben Bellows at bbellows@popcouncil.org 